\title{
WACANA ISLAMOPHOBIA DAN PERSEPSI TERHADAP ISLAM INDONESIA MELALUI STUDI BAHASA DI KALANGAN MAHASISWA POLANDIA
}

\author{
Jauharoti Alfin, Achmad Muhibbin Zuhri, Zudan Rosyidi \\ Fakultas Tarbiyah dan Keguruan UIN Sunan Ampel Surabaya \\ Jl. A Yani No.117 Surabaya, Jawa Timur, 60237 \\ e-mail: alfin@uinsby.ac.id, amizuhri@gmail.com, zudanrosyidi1@gmail.com
}

\author{
Dorotea Moni Stelmachowska \\ Universitas Adam Mickiewics Polandia \\ Wieniawskiego 1, 61-712 Poznañ, Polandia \\ e-mail: doroteas@amu.edu.pl.
}

\begin{abstract}
Abstrak: Artikel ini mengkaji persepsi mahasiswa Adam Mickiewicz of University tentang Islam di Indonesia. Pengetahuan menjadi variabel yang berperan dalam mempersepsikan Islam di Indonesia melalui proses perkuliahan BIPA. Melalui keterampilan berbahasa Indonesia, mahasiswa ini memiliki kemampuan memperoleh informasi yang pada akhirnya membentuk pengetahuan tentang Islam Indonesia. Kombinasi antara pengetahuan dan bahasa inilah yang menjadikan ide dan gagasan mereka tentang Islam di Indonesia, baik lisan maupun tulisan, dapat terbaca dan dianalisis oleh penulis. Secara implisit ancangan analisis wacana kritis digunakan sebagai kerangka untuk mengembangkan tulisan ini. Pendekatan ini menempatkan teks berbahasa tidak dalam kerangka interpretif namun lebih bersifat kontekstual.
\end{abstract}

\begin{abstract}
Islamophobia Discourse and Perceptions of Indonesian Islam Through Language Studies among Polish Students. This article analyzes the perception of Adam Mickiewicz of University students about Islam in Indonesia. Knowledge becomes a variable that plays an important role in perceiving Islam in Indonesia through BIPA lecture process. With Indonesian language skills, this student has the ability to obtain information that ultimately forms the knowledge of Indonesian Islam. The author analyzes the combination of knowledge and language both oral and written that he claims to have contributed to the creation of ideas as well as ideas about Islam in Indonesia. The Critical Discourse Analysis is implicitly used as a framework for developing this paper. This approach places language texts not in an interpretive framework but rather in a more contextual character.
\end{abstract}

Kata Kunci: Islamophobia, Islam Indonesia, mahasiswa Polandia 


\section{Pendahuluan}

Polandia menjadi salah satu negara yang tidak luput dari pengaruh meluasnya gerakan Islamophobia di Eropa. Menariknya keberadaan komunitas Muslim di Polandia sangat kecil jika dibandingkan dengan negara Eropa lainnya. Oleh karena jumlah tersebut, terdapat sebagian akademisi yang mengatakan bahwa Islamophobia yang berkembang di Polandia sebagai Islamophobia without Muslim community or platonic phobia. ${ }^{1}$ Artinya, phobia yang muncul di masyarakat Polandia tidak didahului dengan adanya pengalaman pribadi negatif, persaingan di pasar kerja, atau kesan buruk ketika berinteraksi di ruang publik dengan komunitas Muslim. ${ }^{2}$

Salah satu cara yang dapat digunakan untuk menjelaskan berkembangnya Islamophobia di Polandia adalah dengan mengidentifikasi akar permasalahannya. Penulis mencatat ada tiga sumber yang berakibat pada munculnya phobia tersebut. Pertama, struktur masyarakat yang cenderung homogen. Dengan jumlah 96 persen warga menyatakan kepatuhan kepada Gereja Katolik Roma, Polandia adalah salah satu negara paling homogen di Uni Eropa. Tidak ada informasi yang pasti tentang jumlah populasi Muslim di negara berpenduduk 38 juta jiwa, tetapi diperkirakan jumlahnya antara sekitar 25.000 hingga 35.000 orang. ${ }^{3}$

Dalam perspektif Pêdziwiatr, homogenitas masyarakat itu berakibat pada minimnya kontak masyarakat Polandia dengan komunitas Muslim. Hanya satu atau dua dari sepuluh orang Polandia yang pernah melakukan kontak dengan komunitas Muslim dan sifatnya pun temporal, seperti ketika mereka melakukan kunjungan ke negara-negara Islam seperti Turki dan Mesir. Pendapat yang sama dapat dibaca pada hasil penelitian yang dilakukan oleh salah satu Pusat Penelitian di Universitas Warsawa yang menyatakan bahwa ada 80 persen orang Polandia yang tidak mengenal Islam, dan 73 persennya memiliki pandangan negatif terhadap Islam. ${ }^{4}$

Kedua, propaganda anti-Islamisme yang berkembang di media Polandia menjadi sumber berikutnya yang memperkuat Islamophobia. ${ }^{5}$ Media telah mengidentikkan Islam dengan Osama bin Laden, pemboman World Trade Center (WTC), sumber terorisme, perang Timur Tengah, dan bentuk-bentuk kekerasan lain. ${ }^{6}$ Stigma ini diperkuat dengan gambaran

${ }^{1}$ Renata Wloch, "Islam in Poland," dalam International Journal of Sociology, 39: 3, 2014 , h. 58-67.

${ }^{2}$ Michal Buchowski, "Making Anthropology Matter in the Heyday of Islamophobia and the 'Refugee Crisis': The Case of Poland," dalam Etnologicky Casopis, Vol. 103, Issue 1, 2016, h. 61.

${ }^{3}$ Konrad Pêdziwiatr, "Muslims in Contemporary Poland," dalam J. Bureš (ed.), Muslims in Isegrad Countries (Prague: Anna Lindh Foundation and Visegrad Fund, 2011), h. 10-24.

${ }^{4}$ Konrad Pêdziwiatr, "Islamophobia in Poland: National Report 2016", dalam Enes Bayraklý dan Farid Hafez, European Islamophobia Report 2016 (Istanbul: SETA, 2017), h. 418.

${ }^{5}$ B. Bachman, "Diminishing Solidarity: Polish Attitudes toward the European Migration and Refugee Crisis," dalam Enes Bayrakli dan Farid Hafez, European Islamophobia Report 2015 (Istanbul, SETA, 2016), h. 417.

${ }^{6}$ Negara Eropa melihat Islam sebagai sumber terorisme dan kekerasan dari pada konteks 
media bahwa Muslim direpsentasikan sebagai orang-orang yang tidak dapat atau tidak bisa berintegrasi dengan masyarakat Eropa, dan agamanya tidak sesuai dengan nilainilai Barat tentang kebebasan dan persamaan. ${ }^{7}$ Perilaku-perilaku ini dianggap sebagai inti dari ajaran Islam yang dianggap mengancam pranata sosial kehidupan masyarakat Barat yang sudah mapan. Bentuk phobia ini diperparah oleh kondisi di mana tidak cukup banyak akses pengetahuan tentang Islam dan komunitas Muslim sebagai diskursus tandingan terhadap identifikasi Islam itu. ${ }^{8}$ Kondisi itu digambarkan oleh Bayrach dan Hafez dengan menuliskan bahwa people simply lack basic knowledge on Islam and Muslims practices. ${ }^{9}$

Ketiga, diakibatkan faktor migrasi masyarakat Polandia ke negara Eropa lain berandil pula pada munculnya Islamophobia. Sensus yang dilakukan pada tahun 2011 menunjukkan bahwa hampir 500 ribu lebih masyarakat Poladia yang hidup di Inggris. ${ }^{10}$ Masyarakat yang bermigrasi ke negara Eropa lainnya yang tingkat Islamophobia tinggi akan cenderung bersifat lebih intoleran lagi ke kelompok Muslim di Polandia ketika mereka kembali ke negaranya. Anna Gawlewicz and Narkowicz berargumen bahwa masyarakat Polandia di Inggris lebih sering melakukan kontak dengan kelompok Muslim dan mereka berada pada masyarakat Inggris yang memiliki pandangan yang sudah mapan terhadap kelompok Muslim, yang dalam beberapa kasus sikap masyarakat kepada imigran mengarah pada bentuk phobia. ${ }^{11}$

Meskipun Islamophia berkembang, namun dengan membaca secara rinci hasil penelitian Pêdziwiatr dan Klimowicz bahwa masih ada gambaran masyarakat Polandia yang tidak terpengaruh dengan Islamophobia. Masih ada kelompok masyarakat yang memiliki persepsi positif dan tidak merasa takut dengan keberadaan komunitas Muslim, karena mereka melakukan kontak dengan masyarakat Muslim ketika berada di luar negeri.

Pandangan dan penerimaan yang positif terhadap Islam menjadi dasar tulisan ini. Mereka adalah mahasiswa program Magister di Institute of Linguistics di Adam Mickiewicz of University Program Bahasa Indonesia Penutur Asing (BIPA) di Ponzan Polandia. Mahasiswa yang secara khusus mempelajari Bahasa Indonesia ini secara tidak langsung belajar Islam ketika belajar bahasa melalui teks yang ada pada sumber belajar dan interaksi langsung dengan pemeluk Islam ketika berkunjung ke lndonesia.

yang melatarbelakanginya, tidak terkecuali Polandia. Lihat Mualimul Huda, "The Project of Islamophobia," dalam Qudus International Journal of Islamic Studies, Vol. 3, Issue 2, August 2015.

${ }^{7}$ Enes Bayraklý dan Farid Hafez, European Islamophobia Report 2015 (Istanbul: SETA, 2016), h. 20.

"Pêdziwiatr, "Muslims in Contemporary Poland," h. 10-24.

${ }^{9}$ Bayraklý \& Farid Hafez, European Islamophobia, h. 9.

${ }^{10}$ Office for National Statistics, "Polish People in the UK-Half a Million Polish Residents," dalam http://www.ons.gov.uk., diakses pada tanggal 25 Januari 2018.

${ }^{11}$ Anna Gawlewicz and Kasia Narkowicz, "Islamophobia on the Move: Circulation of AntiMuslim Prejudice between Poland and the UK," dalam http://biblioteca.universia.net, diakses 25 Januari 2018. 
Pada pemahaman ini, bahasa tidak saja menjadi media untuk memindahkan atau mentransfer pengetahuan bagi mahasiswa. Tidak cukup juga diposisikan sebatas sebagai keterampilan berbahasa (berbicara, menulis, membaca dan mendengarkan), tetapi merupakan sebuah kemampuan olah pikiran mahasiwa yang mewujud dalam beraneka rupa mengikuti tujuan yang termaktub dalam kurikulum atau tujuan perkuliahan. Dengan kata lain, kemampuan berbahasa adalah sebuah mental proses atau bentuk konsep psikologis yang mengikuti kebutuhan individu. ${ }^{12} \mathrm{Hal}$ ini berarti bahasa tidak lagi ditempatkan sebatas pada struktur gramatikalnya saja, karena sebagai kebutuhan kognitif (cognitive need), maka bahasa memosisikan penuturnya untuk "need to find order and meaning in the environment."13 Dengan kata lain, kemampuan berbahasa adalah sebuah mental proses atau bentuk konsep psikologis yang mengikuti kebutuhan individu.

\section{Metode Penelitian}

Tulisan ini merupakan hasil penelitian kolaboratif antara dosen Universitas Islam Negeri Sunan Ampel dengan dosen di program Magister di Institute of Linguistics di Adam Mickiewicz of University Ponzan Polandia. Penelitian ini dilakukan pada tahun 2016 dengan subjek penelitiannya adalah mahasiswa di program studi yang sedang mempelajari bahasa Indonesia.

Salah satu tema dalam penelitian itu kemudian digunakan sebagai bahan untuk tulisan ini. Satu tema penelitian yang diambil adalah seputar hubungan antara wacana Islamophobia dengan persepsi mahasiswa program Magister di Institute of Linguistics di Adam Mickiewicz of University Ponzan Polandia terhadap Islam di Indonesia.

Kerangka penelitian yang digunakan dalam tulisan ini adalah ancangan wacana kritis yang dikembangkan oleh van Dijk digunakan sebagai metode penelitian. Ada dua unit analisis dalam konsep van Dijk, yakni dimensi teks dan dimensi kognisi sosial. Dari dua dimensi itu, hanya dimensi kognisi sosial yang digunakan untuk menjelaskan permasalahan. Bagaimana proses kerja kognisi sosial dalam analisis wacana kritis berjalan? Van Dijk menempatkan kognisi sosial dalam sebuah elemen wacana. ${ }^{14}$ Dimensi kognisi sosial menjelaskan bagaimana suatu teks diproduksi oleh individu/kelompok pembuat wacana. Cara memandang atau melihat suatu realitas sosial itu yang melahirkan wacana tertentu. Yang terakhir melihat bagaimana suatu teks itu dihubungkan lebih jauh dengan struktur sosial dan pengetahuan yang berkembang dalam masyarakat atas suatu wacana.

${ }^{12}$ Wittgenstein, Remarks on The Philosophy of Psychology (Oxford: Blackwell Publishing, 1980).

${ }^{13}$ Eeva-Liisa, "University Students's Information Seeking Behaviour in a Changing Learning Environment," dalam www.shef.ac.uk/infers/isic/eeskola, diakses 12 Februari 2018.

${ }^{14}$ Norman Fairclough, Critical Discourse Analysis (London: Longman, 1997), h. 222. 


\section{Hasil dan Pembahasan}

\section{Islamophobia dan Keberadaan Masyarakat Homogen di Polandia}

Sejak lama masyarakat Polandia telah berdampingan dengan komunitas Islam, jauh sebelum gelombang imigran Arab. Bahkan mereka datang jauh sebelum negara Polandia ada. Mereka adalah para suku pendatang yang datang dari daerah sekitar yang beragama Islam. Mereka menetap dan berkembang dengan budaya dan bahasa sendiri. Namun seiring waktu, budaya dan bahasa asli mereka melebur melalui beragam bentuk asimiliasi dengan masyarakat Polandia. Agama Islam menjadi sisa dari peninggalan komunitas Tartar.

Komunitas Muslim Tatar berhasil melakukan proses asimilasi dengan masyarakat non Muslim di sebuah daerah yang berbeda secara budaya. Mereka menerima gaya hidup dan pandangan masyarakat dan bahkan mengganti bahasa ibu dengan bahasa masyarakat Polandia. Semua proses itu berjalan seiring dengan interaksi komunitas Muslim Tatar dan lingkungannya. Satu hal yang masih tersisa adalah mereka tetap menganut Agama Islam. ${ }^{15}$ As only religion is an element differentiating Polish and Tatars, there are not many conflictor situations. Tatars do not complain of wrong treatment or any signs of discrimination. ${ }^{16}$ Akar budaya yang terintegrasi dengan budaya masyarakat Polandia berakibat mereka dapat diterima di tengah-tengah masyarakat.

Dalam perkembangannya, Polandia kedatangan lagi kelompok Muslim selain Tatar. Ada dua alasan yang melatarbelakangi kedatangan kelompok pendatang ini. Pertama, adalah kelompok Muslim yang datang ke Polandia dalam rangka melakukan bisnis dan kemudian menetap. Kedua, adalah para pengungsi dari wilayah yang sedang mengalami peperangan seperti Chechnya, Syria dan Irak. Dari dua kelompok itu yang mendapatkan tentangan dari masyarakat adalah yang kedua yang dianggap sebagai ancaman dan "orang luar" dan dikaitkan dengan pembunuhan orang Polandia, yakni tentara yang berpartisipasi dalam operasi militer di Irak dan Afghanistan, dan yang menjadi korban serangan teroris di beberapa negara di luar Polandia. ${ }^{17}$ Kelompok Muslim yang datang belakangan ini dianggap tidak berhasil untuk berakulturasi seperti kelompok pertama yang kemudian dianggap sebagai ancaman terhadap masyarakat Polandia.

Mempertahankan tradisi sebagai sebuah negara yang homogen menjadi ide yang membuat masyarakat Polandia sensitif dengan kedatangan para imigran Muslim pasca komunitas Tartar. Mereka yang telah mengidentikkan diri dengan tradisi Katolik Roma menempatkannya tidak saja sebatas sebagai kepercayaan, namun telah berkembang

${ }^{15}$ Marek M. Dziekan, "History and Culture of Polish Tatars in Muslims," dalam Katarzyna Górak-Sosnowska (ed.), Poland and Eastern Europe Widening the European Discourse on Islam (Warsawa: University of Warsaw Faculty of Oriental Studies Warszawa, 2011), h. 38.

${ }^{16}$ Wojciech Janicki, the Distribution and Significance of Tatar Ethnic Group in Poland (Zaklad Geografi Regionalnej: Instytut Nauk Ziemi UMCS, 2016).

${ }^{17}$ Pêdziwiatr, "Muslims in Contemporary Poland," h.421. 
sebagai nilai-nilai kehidupan masyarakat yang dianggap mampu mengkohesikan seluruh elemen masyarakat. Dalam konteks ini, kedatangan imigran yang sebagian besar dari jazirah Arab dianggap menjadi ancaman untuk tata kehidupan sosial yang sudah dianggap mapan tersebut. Kedatangan para imigran ini dianggap dapat merusak sistem sosial homogen yang sudah berjalan. Karena imigran ini dianggap sama dengan komunitas Muslim yang tergabung dengan kelompok radikal Islam.

\section{Persepsi tentang Islam: Perbandingan Muslim di Indonesia dan Polandia}

Dari beberapa sumber belajar Bahasa Indonesia, internet menjadi media yang paling penting dalam memberikan informasi atau pengetahuan Islam Indonesia bagi mahasiswa. Buku pembelajaran lebih berorientasi pada penguatan kompetensi keterampilan berbahasa Indonesia. Minimnya informasi tertutupi dengan tugas yang terstruktur dari dosen pengampu yang secara tidak langsung berkaitan dengan kontek penuturnya yakni masyarakat Indonesia yang beragama Islam.

Internet telah mendekatkan mahasiswa Polandia dengan realitas Islam Indonesia melalui media sosial. Fungsi media sosial menjembatani ketiadaan konteks bahasan yang hilang yakni dalam situasi tutur tertentu tidak semua individu memiliki kemampuan untuk mendapatkan informasi secara mendalam. Dalam beberapa kesempatan diskusi dengan mahasiswa, didapatkan informasi bahwa para mahasiswa ini berteman secara online dengan masyarakat Indonesia. Islam di Indonesia menjadi topik dalam komunikasi. Bingkai berkomunikasi ini, memungkinkan mereka memiliki akses untuk mengklarifikasi pokok bahasan Islam yang terbit di media masa di Polandia dengan yang terjadi di Indonesia.

Dengan memahami beragam proses belajar tersebut, tidak salah jika muncul kesadaran kritis di kalangan mahasiswa program BIPA di Universitas Adam Mickiewicks Polandia melihat realitas Islam di Indonesia yang "berbeda" dengan Islam yang ada di Polandia. Dari segi apapun memiliki banyak perbedaan. Muslim Indonesia menjadi kelompok mayoritas yang berbeda dengan Muslim di Polandia. Tentunya mereka memiliki akses ekonomi dan politik yang lebih besar yang membuat mereka berpikir ulang untuk bertindak radikal. Sebuah kondisi yang berkebalikan dengan situasi Muslim di Polandia.

Dalam sebuah laporan penelitian disebutkan bahwa phobia terhadap Islam di kalangan masyarakat Polandia tidak seratus persen disebabkan oleh faktor luar seperti serangan terorisme yang berkembang di Eropa, namun lebih karena didorong oleh ketakutan atas ketidakberdayaan Muslim Polandia untuk melawan label dan stigmatisasi yang diakibatkan oleh jumlah yang kecil dan sumber keuangan yang lebih rendah dibandingkan dengan komunitas lainnya. ${ }^{18}$ Ditambah lagi hampir semua informasi yang memenuhi sebagian besar pemikiran masyarakat Polandia adalah hasil dari pemberitaan media yang tidak

${ }^{18}$ Ibid. 
melihat secara menyeluruh dan kritis terhadap realitas Islam yang berkembang di luar Polandia. Islam dalam pandangan media ini diidentikkan dengan kekerasan dan intoleran dengan komunitas lain. Keputusasaan atas situasi sosial ekonomi yang tidak berpihak pada komunitas Muslim itu lebih ditakutkan menjadi pendorong utama kelompok Muslim menjadi radikal daripada pengaruh ideologi dari luar kelompok. ${ }^{19}$

Dengan mengesampingkan terorisme di Eropa dan konten media yang menyuarakan phobia terhadap Islam. Salah satu media yang paling banyak digunakan adalah internet. One of the Facebook groups that gathered a particularly significant following is called "No to the Islamisation of Europe" and is linked to the website Ndie.pl. Its Polish Facebook page has almost 270,000 followers. ${ }^{20}$ Untuk meminimalkan persepsi negatif itu, muncul pula grup di media sosial yang mencoba memberikan klarifikasi atau pemahaman tentang Islam. Górak-Sosnowska menemukan bahwa dalam forum diskusi internet di Polandia terdapat peserta yang pada awalnya menolak Islam dan berubah membela Islam setelah mengikuti forum diskusi. ${ }^{21}$

Berbeda dengan kalangan awam, mahasiswa program BIPA di Universitas Adam Mickiewicks Polandia memahami bahwa Muslim Indonesia tidak identik dengan kekerasan. Misalnya, mereka mengetahui Muslim Indonesia sebagai masyarakat yang lebih ramah dan mudah tersenyum dan praktik keberagaman antar pemeluk agama yang harmonis. Meskipun demikian mereka mencemaskan perkembangan terakhir Islam di Indonesia. Krzysztof Kowalski ${ }^{22}$ menuliskan pendapatnya tentang Islam Indonesia, “orang-orang biasanya berpikir bahwa kalau orang beragama Islam, dia terkait dengan terorisme. Tetapi itu tidak benar. Muslim di Indonesia sangat berbeda dengan Muslim Barat. Orang Indonesia sangat baik dan selalu tersenyum." Islam dalam kacamata Kowalski terletak pada karakter. Mudah tersenyum dan berperilaku baik terhadap orang lain. Jika ditelusuri pada beberapa riset di Polandia, muncul identifikasi Islam yang tidak ramah atau mudah ramah. Fakta inilah yang membuat Kowalski menyatakan bahwa Islam di Indonesia berbeda dengan Islam di Barat.

Stelmachowska, salah satu dosen Bahasa Indonesia berkebangsaan Polandia, menyatakan bahwa maraknya aksi-aksi kekerasan dan "penindasan kaum minoritas" oleh sekelompok kecil aktivis Muslim telah membentuk pemahaman mahasiswa Polandia bahwa, wajah indah Indonesia sebagai negara yang toleran semakin pudar. ${ }^{23}$ Pemahaman

${ }^{19}$ Wloch, Islam in Poland, h. 61.

${ }^{20}$ Pêdziwiatr, "Muslims in Contemporary Poland," h. 435.

${ }^{21}$ Katarzyna Górak-Sosnowska, "Deconstructing Islamophobia in Poland: Story of an Internet Group," dalam Journal of Religion, Media and Digital Culture, Vol. 5, Issue 1, 2016, h. 32.

${ }^{22}$ Mahasiswa ini berumur 32 tahun dan sudah 3 (tiga) tahun belajar Bahasa Indonesia dan pernah berkunjung ke Indonesia sebanyak dua kali. Durasi waktu yang cukup lama dalam belajar bahasa Indonesia dan mengenal masyarakatnya.

${ }^{23}$ Dorotea Moni Stelmachowska, Wawancara, Kamis 28 Januari 2016. 
ini merupakan hasil interaksi secara langsung ataupun tidak langsung melalui proses media sosial. Dua hal yang dipahami oleh Stelmachowska. Pertama, Indonesia adalah negara toleran. Kedua, adalah munculnya ancaman terhadap kehidupan masyarakat minoritas. Perbandingan antara kondisi di Indonesia dengan Polandia sudah tentu merupakan satu hal penting dalam melihat Islam di Indonesia dalam kacamata mahasiswa. Proses perbandingan ini menandakan bahwa kehadiran satu diskursus berpotensi untuk diikuti dengan adanya diskursus lain yang sifatnya dapat memperkuat atau bahkan menegasikan diskursus tersebut. ${ }^{24}$ Persis dengan konsep ini, diskursus Islam yang intoleran tidak serta merta menjadi satu-satunya pengetahuan yang berkembang di Polandia. Masih ada ruang sosial di antara kelompok-kelompok meskipun keberadaannya mulai terancam.

Memburuknya situasi keberagamaan yang diakibatkan oleh radikalisme dan terorisme Islam di Indonesia juga dikuatkan oleh Palandi, dosen BIPA berkebangsaan Indonesia. Ia memiliki pemahaman bahwa, "isu gerakan, jaringan, dan ajaran fundamentalisme dan radikalisme Islam telah menyusup di Indonesia." Bahkan, mahasiswa Polandia program BIPA juga menangkap pesan pemberitaan tentang adanya "gerakan dan jaringan terorisme yang telah menyusup dalam pendidikan agama, dan menjadi sesuatu yang amat menakutkan bagi mereka." 25

Pemahaman tentang terorisme itu tidak serta merta mengarah pada kesimpulan bahwa Indonesia adalah negara teroris. Aleksandra Konieczna menuturkan pemahamannya tentang terorisme yang berkembang di Indonesia lebih kecil dibandingkan dengan yang terjadi di Eropa. ${ }^{26}$ Tidak semua orang Islam adalah teroris. Lebih jauh lagi, ia menuturkan bahwa terorisme di Eropa lebih banyak terjadi dibandingkan dengan di Indonesia. Terkait dengan negara Islam, ia tidak mengetahui dengan detil apakah itu menjadi kehendak semua masyarakat Muslim Indonesia, karena Musim yang dikenalnya masih meneruskan tradisi lama Indonesia selain agamanya yang hal itu tidak mencerminkan pendapat dan perilaku Islam yang radikal. Pendapat yang sama dikemukan oleh Dominika Lubiriska (49 tahun). ${ }^{27}$ Ia mengatakan, "di Indonesia sudah ada terorisme, tetapi banyak orang dari negara itu yang suka perdamaian. Beberapa orang menjadi teroris karena persoalan

${ }^{24}$ Pierre Bouerdie menjelaskan bahwa keberadaan sebuah diskursus pusat (ortodoxa), pasti akan diiringi dengan kehadiran diskursus pinggiran (heterodoxa) yang berusaha untuk menjadi diskursus pusat. Keduanya jenis diskursus ini selalu bertarung dan saling menegasikan. Lihat Pierre Bourdieu, Arena Produksi Kultural: Sebuah Kajian Sosiologi Budaya, terj. Yudi Santosa (Bantul: Kreasi Wacana, 2012).

${ }^{25}$ Esther Hesline Palandi, Wawancara, 27 Januari 2016.

${ }^{26}$ Informan ini adalah salah satu mahasiswa Magister Linguistik yang berumur 21 tahun dan pernah sekali ke Indonesia dan belajar bahasa Indonesia internet, buku-buku Indonesia, dan teman-teman dari Indonesia, memiliki struktur bahasa yang sama dengan Kowalski, wawancara, Kamis 28 Januari 2016.

${ }^{27}$ Informan ini adalah salah satu mahasiswa Magister Linguistik yang belum pernah ke Indonesia dan persinggungannya dengan lingkungan belajar juga masih singkat mengingat ia masih duduk di semester 1, wawancara, Jumat, 29 Januari 2016. 
ekonomis." Sekali lagi proses interaksi dengan Muslim Indonesia menjadi pembanding yang efektif untuk memahami Islam Indonesia. Tidak sama dan memiliki karakteristik khas yang tidak mereka temukan di Polandia pada khususnya dan Eropa pada umumnya.

Beragam isu yang berkutat dengan kekerasan Islam coba diklarifikasi oleh dosendosen BIPA berkebangsaan Indonesia di Polandia. Penjelasan yang bersifat counter-discourse lebih bersifat reaktif, misalnya, menjawab pertanyaan mahasiswa yang muncul selama perkuliahan berlangsung. Belum ada usaha sistematis misalnya dengan memberikan pemahaman lebih utuh tentang Islam dan masyarakat Indonesia melalui kurikulum pembelajaran. Beberapa upaya untuk mengenalkan Indonesia melalui pagelaran budaya dilakukan seperti pemutaran video dan peragaan langsung budaya seperti batik, angklung, wayang kulit, tari piring, tari saman, songket, dan wayang golek. Namun, Islam Indonesia di dalamnya belum terekspos secara mendalam. ${ }^{28}$

Teja Gumilar, salah dosen BIPA berkebangsaan Indonesia, menuturkan hal yang sama terkait usaha dosen untuk men-counter balik isu radikalisme Islam. Menurutnya fenomena radikalisme Islam di Indonesia berhasil membentuk kecemasan mendalam mahasiswa di Polandia. Ia menggambarkan bahwa "para mahasiswa UAM (University of Adam Mickiewicz) sering menanyakan tentang radikalisme agama di Indonesia, mengingat kejadian Bom Bali tahun 2002 dan 2005, fenomena syariah di Aceh serta aksi-aksi Front Pembela Islam (FPI). ${ }^{29}$

\section{Diskursus Multikulturalisme dan Islam Indonesia yang Toleran}

Konsep diskursus Fairclough sangat cocok untuk menggambarkan kekinian masyarakat Polandia yang menjadi phobia dengan Islam. Beragam diskurus berkembang dan mempengaruhi pandangan dan sikap terhadap komunitas Muslim di Polandia yang berakibat pada munculnya tindakan pembatasan dan diskriminasi terhadap kelompok Islam menjadi lazim terjadi di Polandia. ${ }^{30}$

Lingkungan belajar terindikasi turut mengkonstruk pengetahuan mahasiswa Poland tentang Islam di Indonesia. Sebagian dari mereka menyatakan pernah berkomunikasi langsung dengan penutur asli Bahasa Indonesia melalui jejaring sosial internet dan datang langsung ke Indonesia. Kunjungan ke Indonesia merupakan bagian dari pelaksanaan kurikulum pembelajaran di program Magister di Institute of Linguistics di Adam Mickiewicz of University di Ponzan Polandia untuk memperkuat keterampilan berbahasa.

${ }^{28}$ Nani Darmayanti, "Pengajaran Bahasa di Warsawa: Suatu Bentuk Diplomasi-Budaya Indonesia di Polandia," dalam Prosiding dan Makalah Kongres Bahasa Indonesia X, 28-31 Oktober 2013 (Jakarta: Badan Pengembangan dan Pembinaan Bahasa-Kementerian Pendidikan dan Kebudayaan, 2013), h. 7.

${ }^{29}$ Desy Teja Gumilar, Wawancara, Jum'at 29 Januari 2016.

${ }^{30}$ Enes Bayrakli dan Farid Hafez, European Islamophobia, h. 234. 
Untuk keberhasilan mereka tinggal di rumah masyarakat untuk belajar langsung bahasa Indonesia. Metode ini mengantarkan mereka tidak saja pada pemerolehan keterampilan berbahasa, namun juga pada pemahaman aspek sosial budaya yang ada di dalam masyarakat.

Dapat ditegaskan bahwa bentuk interaksi sosial antara mahasiswa dengan masyarakat Indonesia ini memperkuat konteks kemunculan teks pertanyaan yang diajukan mahasiswa. ${ }^{31}$ Konteks dapat berfungsi untuk menghantarkan pemahaman atas sebuah teks dengan melihat relasi atau variabel di luar kebahasaan yang melingkupi teks sehingga menjadi bermakna ketika dilihat sebagai proses yang terus menerus dan terhubung dengan lingkungan berbahasa. Sederhananya teks adalah bahasa yang berfungsi untuk menyatakan apa saja yang ada dalam pikiran seorang individu. ${ }^{32}$

Setidaknya ada beberapa mahasiswa yang pernah mengunjungi Indonesia dan ternyata memiliki pemahaman yang luas tentang kondisi sosial masyarakat Indonesia yang multi etnik dan agama. Bahkan satu di antara mereka mengenal dan mengetahui bentuk semboyan negara, yakni Bhinneka Tunggal Ika yang secara tersurat menggambarkan bagaimana struktur sosial masyarakat Indonesia.

Bagi mahasiswa yang belum ke Indonesia, juga memiliki pandangan yang sama seperti yang dituturkan Dominika Lubiriska (49 tahun), 33 "Indonesia adalah negara multi agama di dunia di samping Malaysia, Singapura dan negara lain. Di sana lebih dominan agama Islam, tetapi juga ada agama Kristen, Hindu, Buddha. Mereka hidup berdampingan dan saling menghargai satu sama lain."

Pengetahuan atas Islam Indonesia yang utuh ini didapatkan beriringan ketika ia memperkuat kompetensi berbahasa Indonesia. Ia belajar bahasa Indonesia dengan berbicara dengan orang-orang dari Indonesia melalui chatting di media internet, menonton film Indonesia, dan mendengarkan lagu-lagu Indonesia.

Lebih dalam lagi adalah analisa yang dilakukan oleh Dominika terhadap Islam di Indonesia adalah perilaku sebagian orang Islam yang berusaha memaksakan kehendaknya dalam urusan publik. Ia mengatakan "mungkin ada orang yang menganggap agama minoritas harus tunduk pada agama mayoritas, tetapi lebih banyak orang menghargai

${ }^{31}$ Penulis lebih melihat proses kunjungan yang dilakukan oleh mahasiswa Poland ini sebagai bentuk interaksi social daripada sekadar proses komunikasi. Atau dengan kata lain, komunikasi hanya menjadi salah satu proses yang terjadi selama mahasiswa di Indonesia. Dengan demikian selama interaksi mahasiswa tidak sekadar belajar atau memperkuat ketrampilan berbahasa saja, namun juga belajar secara tidak langsung kehidupan sosial masyarakat yang ditempatinya selama Indonesia. Istilahnya mahasiswa selama lived in melakukan proses participation observation terhadap aktivitas masyarakat.

${ }^{32}$ M.A.K Halliday dan Ruqaiya Hasan, Bahasa, Konteks, dan Teks: Aspek-Aspek Bahasa dalam Pandangan Semiotik Sosial (Yogyakarta: Gajah Mada University Press, 19941), h. 13.

${ }^{33}$ Informan ini adalah salah satu mahasiswa Magister Linguistik yang berada di semester I dan belum pernah berkunjung ke Indonesia, wawancara, Kamis, 28 Januari 2016. 
minoritas". Tidak seratus persen percaya dengan pemberitaan media karena ia pernah melihat secara langsung bagaimana kebhinnekaan Indonesia ketika berkunjung ke Indonesia dan tinggal di rumah penduduk yang memiliki kepercayaan berbeda dengannya.

Jika merujuk pada konsep diskursus yang diberikan oleh Fairclough yang sifatnya dua arah, pengetahuan atas Islam di Indonesia dibarengi dengan pemahaman atas konteks dan diskursus lain yang melingkupi berupa diskursus multikultarisme. Konteks yang dimaksud di sini adalah konteks sosial, politik, ekonomi dan budaya. ${ }^{34}$ Eriyanto menggambarkan bahwa model diskursus yang dikembangkan oleh Fairclough berusaha mendeteksi dan menghubungkan satu diskursus dengan diskursus yang lain yang terjadi dalam masyarakat. ${ }^{35}$ Dalam satu realitas masyarakat dimungkinkan adanya lebih dari satu diskursus.

Kehadiran diskursus multikultural di antara mahasiswa itu dibarengi dengan pemahaman atas diskursus lain, yakni diskursus yang berkembang di level pemerintahan, yakni diskursus kebangsaan Indonesia. Mahasiswa mengetahui bahwa ideologi Pancasila dengan moto Bhinneka Tunggal Ika menjadi visi bersama yang menyatukan masyarakat Indonesia. Secara jeli hal itu dipahami oleh Krzysztof Kowalski. ${ }^{36}$ Visi itu terangkum dalam konsep kenegaraan Indonesia. Kowalski mengatakan bahwa di Indonesia ada semboyan Bhinneka Tunggal Ika. "Tidak ada masalah kalau ada orang yang agama berbeda tidak harus tunduk pada agama mayoritas," kata Kowalski di perpustakaan Universitas Adam Mickiewicks.

Lalu, ia bercerita jika pada kunjungan yang kedua ia tinggal di rumah masyarakat yang penghuninya menganut agama yang berbeda-beda, Kristen dan Islam. "Saya tahu orang Indonesia dari satu keluarga. Satu dari mereka adalah orang Kristen, yang kedua adalah orang Muslim dan tidak ada masalah." Rangkuman pengetahuan mahasiswa atas kondisi Indonesia itu merupakan salah satu bentuk bagaimana pengetahuan tentang falsafah kebhinnekaan yang termanifestasikan dalam tindakan. Karena itu, ia tidak sepakat dengan negara Islam karena Bhinneka Tunggal Ika berarti ada kebebasan di Indonesia. Dalam satu sesi diskusi ringan, ia mengatakan bahwa jika ada orang Indonesia menginginkan berdirinya negara Islam itu sama saja dengan mengingkari eksistensi negara yang sudah merdeka.

Tentunya pemahaman yang dalam tentang Indonesia menuntun untuk mengetahui bagaimana pengetahuan itu diperoleh. Hampir sama dengan lain, Kowalski tidak menyandarkan pada satu sumber belajar. Pengetahuan yang luas didukung oleh aktivitas belajar lain. Selain teks buku pembelajaran, Kowalski membaca buku-buku bahasa Indonesia lain dan membaca berita di situs online, salah satunya yakni www.kompas.com.

${ }^{34}$ Ibid., h. 9. h. 328.

${ }^{35}$ Eriyanto, Analisis Diskursus: Pengantar Analisis Teks Media (Yogyakarta: LKiS, 2001),

${ }^{36}$ Informan ini adalah salah satu mahasiswa Magister Linguistik yang berusia 32 tahun yang belajar bahasa Indonesia selama 3 tahun dan pernah berkunjung ke Indonesia sebanyak dua kali. 
Meskipun demikian, masih ada satu hal krusial yang cukup menggangu dari pemahaman mereka tentang Islam, yaitu pengetahuan Islam yang tidak lengkap. Pada dasarnya mereka adalah mahasiswa yang belajar bahasa Melayu dan bahasa Indonesia. Artinya mereka disiapkan untuk menjadi ahli bahasa bukan kajian keislaman. Namun, karena bahasa Melayu dan bahasa Indonesia sebagian besar penuturnya adalah muslim otomatis memaksa mereka untuk bersinggungan dengan pengetahuan Islam yang sering menjadi konten dari sumber media belajar yang digunakan.

\section{Penutup}

Homogenitas menjadi kerangka berpikir dan melihat Islam di Polandia. Nilai yang dibentuk untuk menaungi dan menjaga sistem sosial dianggap terancam ketika Muslim Arab masuk ke Polandia, baik sebagai pengungsi ataupun yang memiliki kegiatan bisnis. Terlebih lagi dengan aksi-aksi teror yang menimpa masyarakat Barat dan khususnya terbunuhnya tentara Polandia di Timur Tengah. Kondisi inilah yang memunculkan phobia terhadap Islam, meskipun mereka tidak pernah mengalami atau berinteraksi dengan komunitas Muslim.

Dalam lingkup yang kecil, terdapat sekelompok mahasiswa yang tidak melihat Islam dalam bingkai masyarakat Polandia. Mereka ini melihat Islam di Indonesia tidak seperti yang digambarkan di media di Polandia. Sebagai kekuatan mayoritas yang mampu hidup berdampingan dengan damai, bahkan dapat mengayomi untuk komunitas "yang lain". Islam Indonesia menampilkan wajah yang berbeda, baik secara fisik maupun budaya.

Mereka menemukan karakter yang berbeda. Mudah tersenyum dan berperilaku baik terhadap orang lain. Jika ditelusuri pada beberapa penelitian di Polandia, muncul identifikasi Islam yang tidak ramah atau mudah ramah. Fakta inilah yang membuat Kowalski menyatakan bahwa Islam di Indonesia berbeda dengan Islam di Barat.

\section{Pustaka Acuan}

Bachman, B. "Diminishing Solidarity: Polish Attitudes toward the European Migration and Refugee Crisis," dalam Enes Bayrakli dan Farid Hafez, European Islamophobia Report 2015. Istanbul: SETA, 2016.

Bayrakli, Enes, dan Farid Hafez. European Islamophobia Report 2015. Istanbul: SETA, 2016.

Bourdieu, Pierre. Arena Produksi Kultural: Sebuah Kajian Sosiologi Budaya, terj. Yudi Santosa. Bantul: Kreasi Wacana, 2012.

Buchowski, Michal. "Making Anthropology Matter in the Heyday of Islamophobia and the 'Refugee Crisis': The Case of Poland," dalam Etnologicky Casopis, Vol. 103, Issue 1, 2016. 
Darmayanti, Nani. "Pengajaran Bahasa di Warsawa: Suatu Bentuk Diplomasi-Budaya Indonesia di Polandia," dalam Prosiding dan Makalah Kongres Bahasa Indonesia X, 28-31 Oktober 2013. Jakarta: Badan Pengembangan dan Pembinaan BahasaKementerian Pendidikan dan Kebudayaan, 2013.

Dziekan, Marek M. "History and Culture of Polish Tatars in Muslims," dalam Katarzyna Górak-Sosnowska (ed.). Poland and Eastern Europe Widening the European Discourse on Islam. Warsawa: University of Warsaw Faculty of Oriental Studies Warszawa, 2011.

Eeva-Liisa. “University Students's Information Seeking Behaviour in a Changing Learning Environment," dalam www.shef.ac.uk/infers/isic/eeskola, diakses 12 Februari 2018.

Eriyanto. Analisis Diskursus: Pengantar Analisis Teks Media. Yogyakarta: LKiS, 2001.

Fairclough, Norman. Critical Discourse Analysis. London: Longman, 1997.

Gawlewicz, Anna, dan Kasia Narkowicz. "Islamophobia on the Move: Circulation of AntiMuslim Prejudice between Poland and the UK," dalam http://biblioteca.universia.net, diakses 25 Januari 2018.

Górak-Sosnowska, Katarzyna. "Deconstructing Islamophobia in Poland: Story of an Internet Group," dalam Journal of Religion, Media, and Digital Culture, Vol. 5, Issue 1, 2016.

Halliday, M.A.K dan Ruqaiya Hasan. Bahasa, Konteks, dan Teks: Aspek-Aspek Bahasa dalam Pandangan Semiotik Sosial. Yogyakarta: Gadjah Mada University Press, 1994.

Huda, Mualimul. "The Project of Islamophobia," dalam Qudus International Journal of Islamic Studies, Vol. 3, Issue 2, August 2015.

Janicki, Wojciech. The Distribution and Significance of Tatar Ethnic Group in Poland. Zaklad Geografi Regionalnej: Instytut Nauk Ziemi UMCS, 2016.

Office for National Statistics. "Polish People in the UK-Half a Million Polish Residents," dalam http://www.ons.gov.uk., diakses pada tanggal 25 Januari 2018.

Pêdziwiatr, Konrad. "Islamophobia in Poland: National Report 2016", dalam Enes Bayraklý \& Farid Hafez. European Islamophobia Report 2016. Istanbul: SETA, 2017.

Pêdziwiatr, Konrad. "Muslims in Contemporary Poland," dalam J. Bureš (ed.). Muslims in Isegrad Countries. Prague: Anna Lindh Foundation and Visegrad Fund, 2011.

Wittgenstein. Remarks on The Philosophy of Psychology. Oxford: Blackwell Publishing, 1980.

Wloch, Renata. "Islam in Poland," dalam International Journal of Sociology, 39: 3, 2014.

Esther Hesline Palandi, wawancara, 27 Januari 2016.

Kowalski, Wawancara, 28 Januari 2016.

Desy Teja Gumilar, Wawancara, 29 Januari 2016.

Dorotea Moni Stelmachowska, Wawancara, 28 Januari 2016. 